\title{
Generative Processes and the Electronic Arts
}

\author{
Alan Dorin \\ Centre for Electronic Media Art, \\ School of Computer Science and Software Engineering \\ Monash University, Clayton, Australia, 3168 \\ aland@cs.monash.edu.au
}

\section{Abstract}

This paper gives a personal perspective on the application and relevance of generative processes to art production. This view is that of a computer programmer, rather than that of a user of computer programs written (or hardware constructed) by others. The programmer is in the unique position of being able to describe and manipulate abstract processes which may be used as a unique means of artistic expression. This gives a greater amount of freedom to the programmer/artist than is the case when he or she is limited by programmed procedures defined by others.

Prior to the development of a formal means of specifying visual and aural events, a concrete machine or set of rules for their manipulation and a means of bringing these representations back into the world as physical events, abstract processes were things to be contemplated but not experienced. Musical and spatial notations employed by artists, engineers and others, in concert with the programming of computing hardware, have opened the way for those who wish to manipulate processes in their artistic practice.

In order to focus study and practice in the area of such generative computer art, the Centre for Electronic Media Art (CEMA) has being established in Melbourne, Australia. The centre has spawned an international conference series on generative/process-based electronic art called "Iteration". The perceived roles of the centre and Iteration conferences are discussed in this paper.

Keywords: generative art, algorithmic art, procedural modelling, algorithmic composition

\section{Introduction}

Much of the time and energy which has been available to humans throughout the ages has been invested in continual and consistent efforts to generate art. 
Leaving aside the possible reasons for this investiture, the author has found a particular means of creating art of all kinds - that of establishing a (computational) process and allowing it to run its course - to be of singular interest. It is this mechanism which is treated below.

This process-based approach to artefact production is here distinguished from other methods of employing processes to art making. Additionally, the properties peculiar to abstract, computational processes are distinguished from those of physical processes. Interest in abstract computational processes and artistic works in which they play a part has led to the formation of a Centre for Electronic Media Art in Melbourne, Australia. The centre has spawned an international conference series entitled Iteration, which examines the issues surrounding the use of computational processes in the electronic arts.

\section{The Centre for Electronic Media Art}

The Centre for Electronic Media Art (CEMA) is a fledgling cross-disciplinary centre for those sharing its interest in writing software as a means of generating art. The centre's interests and aims have yet to be formalized but are to be based around the perceived need to encourage and engage students and researchers in artistic expression, realized through an expertise in algorithmic manipulation.

Especially in the realm of science, it was felt that insufficient weight was given to rigorous research which found its outlet in the arts. CEMA aims to support artists who value the art/science of algorithms. For such work, the process or algorithm is as much the "art" as is any physical or virtual artefact it constructs. Similarly, the science of the algorithm is as important to the work as the production of the artefact or visualization of the process it encapsulates.

CEMA is based within the School of Computer Science and Software Engineering at Monash University. It was founded in 1999 by Alan Dorin and Jon McCormack and incorporates participants from a cross-section of the academic community. CEMA projects involve the School of Music-Conservatorium (through Peter McIlwain), and the Faculty of Art and 
Design (through Troy Innocent). The Faculty of Engineering, the Mathematics Department and the Department of Archaeology are all variously involved in CEMA projects encouraging a diverse, multi-disciplinary approach and wideranging input and output.

Artists and researchers visiting from other institutions are also involved with CEMA and its projects, providing avenues for exchange of researchers, students and ideas across international boundaries. Artist Richard Brown is visiting CEMA from London's Royal College of Art early in 2001 to construct an interactive work based around concepts of self-organization. The author is currently completing a four month project at ATR Research Laboratories in Kyoto, Japan. During this time he worked on an interactive artificial-life and music project conceived by Australian sound-artist Rodney Berry.

There have not been many institutions in Australia supporting, nor targeting, computer-based generative art. Much generative work, in the electro-acoustic music and visual art communities has been produced by individuals in their 'spare' time, often from within larger organizations devoted to the sciences or traditional arts. One such place, the Advanced Computer Graphics Centre (ACGC) existed as an offshoot of the Royal Melbourne Institute of Technology in the late 80's and early 90's. Founded by Gigante, the ACGC, whilst primarily a graphics research laboratory, accommodated numerous students and visual artists including Lescinsky who was involved in L-system and fractal-generated imagery at the time (Lescinsky 1992).

Other work involving fractals and Iterated Function Systems has been completed by Ramsden (Ramsden 1994) and recently McCabe (McCabe 1999) at the Australian Centre for Art and Technology (ACAT). Founded by Worrall at the Australian National University in Canberra, ACAT also supports exploration of generative art, although this is not its specific focus. In 1994, ACAT hosted the "Synaesthetica" conference on computer animation and computer music. This aimed to bring together the computer-music and computer-animation communities in Australia. Although Synaesthetica was dominated by computer-music practitioners, this gathering influenced the thinking which led to the Iteration event some five years later (see below). 
At an individual level, whilst some Australian artists have worked on software for process-based art, most has come from those in the electroacoustic music community. Other papers in this Organized Sound issue will deal specifically with composers. Only a handful of local artists have employed generative techniques beyond those associated with fractals and cellular automata for visual art production. The work of a few is known to the author, many of whom participated in the First Iteration conference.

Tonkin's trilogy of videos air, water parts one to three (Tonkin 1993) explore the properties of air and water through the poetry of their movement. His work These Are The Days is a meditation on the passing of time. Implicit and explicit in his video works are the concepts of fluidity, the movement of processes through space and time. These illustrate an engagement with and devotion to the study of the issues of process-based, generative art. Tonkin's works are not only about process, it is the very stuff of which they are made. Tonkin has also written software for interactive installations such as his Personal Eugenics (Tonkin 1999), which explores, through evolutionary techniques, the establishment of self-identity.

McCormack is best known for his interactive laser-disk work Turbulence (McCormack 1994a) which appeared at the SIGGRAPH art show and electronic theatre and continues to be exhibited in galleries around the world. Other works from McCormack include small and large-scale generative installation pieces and screen-based works. These include Future Garden, a public art work developed as part of Melbourne's Federation Square Precinct (to be completed in 2001), and Wild exhibited on the glass of the front entrance to the National Museum of Victoria (McCormack 1994b).

McCormack's work engages issues concerning our relationship with nature. Works such as Turbulence explore biology and our understanding of living systems through algorithmic instantiation of natural process, the synthesis of behaviour and morphology reminiscent of that found in the physical world. The forms generated by McCormack remain within the artificial constructs of virtual environments, but nevertheless the viewer readily projects the properties of physical, biological space into these digital constructs to witness the interaction of organisms whose life-blood is a flow of information 
manipulated electronically. As with the work of Tonkin, McCormack not only engages with process, the process is quite inextricable from the work.

Paul Brown's work Sandlines (Brown 1999) continues this artist's interest in generative art which he has been persistently exploring since his formative studies in Britain in the late sixties. The process behind Brown's work is one which he has pursued with singular attention... specifically that of removing the artist and replacing him with procedural and logical means of generating a work.

The author has also produced a few short animations including Hydroid Medusae (Dorin 1995), and Ambient5-Music for Casual Encounters (Dorin 1997), as well as interactive installations and still images. He shall not be so selfindulgent as to discuss the concepts behind these works here, since much of this (over long) paper already explores his interests.

\section{The Iteration Conference}

As clearly as the directors of CEMA perceived a lack of avenues for those interested in exploring process-based electronic art, we noted a lack of international events specifically for those engaged in generative computer art of the kind described above. Hence, the First Iteration conference was conceived.

As initiators of the event, we were conscious of the plethora of "Art \& Technology" and even "Art \& Science" conferences and symposia that already exist. There are many established international events including Ars Electronica, SIGGRAPH, ISEA and Art Futura, and even in Melbourne we have seen several endeavours along similar lines. These include two art and technology symposia in 1994 and 1996, organized by the Next Wave Festival. The primary objective of Next Wave is to promote the work of young, emerging Australian artists. Established artists also participate in Next Wave through exhibition and discussion. Some of the Australian generative artists mentioned above contributed works to the '94 and '96 festivals. The '96 ArtTech Symposium was chaired by the author. 
The Modern Image Makers Association was established in 1986 to represent the work of Australian film and video artists. From 1988 to 1996 MIMA held the biennial Experimenta festival which came to encompass new media art of all kinds. In a few cases generative works were included in the program. In 1996 MIMA became Experimenta which continues to hold exhibitions, symposia and fora on new media art and (sometimes) its relationship to science and technology. Besides these large events, countless smaller exhibitions of computer-based screen works have occurred in Melbourne. Occasionally a generative work crops up at one of them but it is usually from one of the established artists working in this area in Australia.

We did not wish to duplicate the domains covered by the multitude of Art/Technology events already in existence. Our focus was limited and specific, perhaps even slightly "nerdy," and certainly we had no idea what the response to our call for participation might be. Fortunately, a group of about 80 individuals from all over the world shared our faith in this idea. We were joined in southern Australia to participate in the inaugural Iteration conference, held early in December 1999.

Conference components included paper presentations, artist talks, performances, a video and film program and a gallery exhibition. Due to the "multiple media" nature of contributions, the published conference materials include an audio CD, a CD-ROM and printed proceedings, some copies of which are still available if Organized Sound readers should wish to buy them (Dorin and McCormack 1999). We encourage anyone interested in this area to participate in Second Iteration, which will be held in our summer, December 2001, Melbourne, Australia.

The First Iteration conference had a strong contingent of computer music participants and we anticipate a similar (or greater) contribution to the second staging of this singular international event. Details about the Iteration conference may be found on its web site at http://www.csse.monash.edu.au/iterate or by email to iterate@csse.monash.edu.au

What follows below is a brief outline of some interests of CEMA and the Iteration conference, and a stream of thoughts on "generative computer art". 


\section{Processes and Algorithms}

A connected sequence of events or actions is termed here a process. Although this is not a definition of the term per se, it serves to illustrate the close links between the concept of a process and that of an algorithm. Whilst the term process is a part of the vernacular, algorithm is perhaps a term most familiar to those with some knowledge of the theory of computation or the practice of computer programming.

The concepts of process and algorithm are closely linked with those of dynamism and change, with becoming. When a process creates a new entity or brings about novel circumstances, it is a generative process with respect to the change(s) it brings about. Why not explore this concept of change through algorithmic means? The modern computer may run identical generative processes repeatedly. It also brings the flexibility to build processes which generate new sequences of events every time it is executed, and processes which respond to environmental and human interference, whilst remaining within boundaries imposed by the programmer.

The sophistication of the virtual machines which may be practically constructed, outweighs that of their purely mechanical counterparts. The flexibility with which computational processes and virtual machines may be constrained and manipulated, exceeds that applicable to biological and chemical processes and machines. The physical, chemical and biological worlds provide an exceedingly wide variety of processes for artistic expression. The virtual realm, whilst arguably less rich, has practicality in its favour. The modern computer is a machine capable of executing processes which may be as interesting for the sequence of changes they generate, as for any final state they bring about. From an artistic standpoint, computers may assist those keen to explore process as an art form.

\section{Three Processes}

Generative processes that occur 'naturally' include those which cause sand to form dunes; produce ripples on a pond, the raging flames of a bushfire and the wind that fans them. All living organisms are defined by the dynamics of 
generative processes. Artists, impressed with the manner in which the natural processes around them have shaped the environment, guide these to shape artefacts of their own. Many natural generative processes are notoriously difficult to guide, yet where they may be contained they have been, and art employing them has flourished.

The Japanese, in their annual Daimonji festival use flames to burn a particular desired kanji mark on a mountainside overlooking Kyoto. Japanese garden designs are also known for the way in which nature's processes are guided to a form envisaged by the designer. Trees are carefully trimmed and wired over hundreds of years to grow into pleasing compositions. Streams are channelled to fall in such a way as to generate particular sounds upon their tumbling into a hollow stone.

Frequently, a process is described as having an 'outcome'. In the case of the process of oil painting, the outcome might be the work as it is exhibited. The "piece of art" is produced at the conclusion of the generative process. The process of production is not something which forms a part of the exhibit. Not all works of art are experienced in this way.

The temporal arts such as cinema, theatre, dance and music are experienced as processes. Just as in the case of painting, there is a process by which the work is constructed or composed. This process occurs behind the scenes and does not form a part of the exhibition. At the conclusion of this process an artefact is produced. Unlike in the case of oil painting, the artefact to be experienced is itself a process rather than a static entity. Interactive computer software may also fit this bill. The programmer sits behind the scenes and writes code to generate a changing world which the viewer may experience.

Whilst notions of audience and performer have been widely challenged by composers such as Cage, in improvised theatre, and in art theory, the distinction remains useful for many art forms. Audiences experiencing a temporal work such as a film or musical composition usually sit for a time until the process reaches a definite conclusion. Some temporal arts allow interactions between audience and performer to alter the process, others do not. In either case, at the conclusion of the process the audience applauds, the performers (if there were any) bow, and everybody exits. If everybody were 
to return to the theatre or auditorium the following evening, essentially the same sequence of events would be repeated. Some, but by no means all, interactive computer software operates in this manner also. Some interactive computer software operates more like a garden...

The experience of a garden is very different to that of a film. The 'audience' might walk through the space or sit awhile. The birds might flutter, the leaves drift and the water flows. A person might disturb the quiet by shouting, they might interact with the flow of water by stepping in the stream. Or they might not. Whatever the audience decides to do, by their presence or their absence the garden will change. If the audience departed to return later, the sequence of events they experienced will not be repeated as if it were a stage play or film. There is no script, the garden flows constantly according to the natural law which audiences are also helpless to obey.

A garden therefore is not usually considered to reach a state of 'completion'. Though its passage through time may be marked by seasonal/cyclic changes and other convenient measures, the garden is intrinsically dynamic, always in a state of becoming.

The painting, the performance and the garden provide three ways of thinking about processes which may be manipulated and applied to art-making. They are intended to be illustrative rather than prescriptive!

\section{Physical and Abstract Processes}

In order to understand the present situation with regard to generative computer art, it is essential to distinguish between physical processes and abstract processes. Physical processes are those that depend for their path on the properties of matter, on causality and the universal laws that govern it. Properties of matter which govern the execution of physical processes include the non-interpenetration of matter, the acceleration of masses acting under force and many, many others. Physical processes are further discussed in (Dorin 1999).

Abstract processes are those which involve the manipulation of symbols or representors. (A representor is a "thing" which represents. A representee is the 
"thing" being represented).Although the substance of a representor such as ink on a page or pebbles on a table, is forced to obey the laws of matter, the meaning of a symbol such as an ink mark or pebble may be any. It is determined only by consensus amongst a group of observers. Abstract processes are therefore changes to a system of representors whose interpretation is made by convention.

\section{Taming Physical Processes}

Physical processes may be represented using static solid artefacts such as oil paintings, dynamic transient artefacts such as musical compositions, or they may be brought into both dynamic and solid form by the construction of kinetic artefacts.

Besides garden design, an example of physically instantiated process-based art has adorned shrines across Asia since ancient times. The wind-chime consists of several pieces of metal, glass, sea-shell, wood or pottery suspended in a location where they may jangle against one another in a breeze. A variation consists of a collection of tubular bells with a central clapper. The clapper is driven by a sail into the suspended columns, causing them to vibrate. Wind-driven clappers may also strike single bells.

The wind-chime is not a device for automatic performance of a pre-arranged work; it is a machine for providing aleatory in composition. Hence it deserves a special place in the history of generative music. Note that the wind-chime's structure dictates the timbres and pitches that it is capable of creating. Although it is capable of producing an infinite variety of sound-events, it may not produce any timbre or sound-event. Is there an equivalent artefact in the world of visual art?

A collection of objects suspended on wires and rods so as to be moved by air currents is called a mobile. Mobiles were introduced to the modern art world by the kinetic artist Calder (Spector 1998:58). Like wind-chimes, mobiles may form an infinite number of patterns in their primary domain of interaction with a viewer. Like the wind-chime, the mobile may not produce any arbitrarily specified physical form. It is constrained by the lengths of its rods and wires, the position at which they are linked, as well as by the kinds of 
suspended objects it includes. Modern mobiles are even more general in their form. The concept of wire-suspended solids has been expanded to include a diverse array of wind-driven kinetic sculptures such as may be found adorning the entrance gardens and open foyers of corporate skyscrapers and council buildings.

If there is any common ancestral technology between generative musical composition and generative visual art, it might well begin with the harnessing of the wind in the wind-chime and mobile.

\section{Musical Notation}

Musical and sound events are by their very nature transient. Short of a calamity, a sculptural work however, will survive from moment to moment without the assistance (or despite the hindrance) of fallible humans, and without the need for documentation besides the artefact itself.

To circumvent the difficulty of preserving and transferring musical compositions, formal systems of notation developed. One of the first forms of musical notation was employed in around 200 B.C.E. by the Chinese to record the music for the seven-stringed zither, the ch'in (Hindley 1987:26). Various other notations have also been developed including of course the limited, but very often useful, staff-based notation of (some) Western music.

When combined with the appropriate instrument, and a skilled musician versed in the conventions for its interpretation, musical notation provides sufficient detail for the reproduction of a series of sound-events.

Recall that an abstract process was described as one in which symbols are manipulated in accordance with their conventional meanings. Hence musical notation provides a formalism from which algorithmic musical composition may develop. This is not the only way process-based music may be created, but algorithms and notation are necessary for composition within the digital realm.

The wind-chime and the mobile are both solid artefacts. They survive and operate consistently from moment to moment during their relatively extensive lifetimes. Despite this property of physical objects, it has been 
beneficial to find formal (and portable) means for their representation. If they should wish to, sculptors, designers, engineers, and architects may draw plans of their artefacts on flat sheets. Clearly they are then employing a notation for sculptural works.

Various conventions exist for the interpretation and production of drawings. Orthogonal views, isometric and other forms of perspective drawing are used to convert between three and two dimensions. The Cubists and Futurists experimented with different ways of doing the same thing. Artists from the indigenous peoples of Australia and North America, or from ancient Egypt, each have their own techniques for creating two dimensional representations of three dimensional forms, particularly the morphology of animals.

The reduction of three physical dimensions into a series of two-dimensional markings on a page, like the process of creating a musical score, is a process of abstraction - the reduction or removal of details. In the case of an orchestral score an enormous amount of information (which nevertheless affects the final sound) is omitted from the document. For example, there is not usually mention made of the techniques for constructing the musical instruments used in the performance. It is assumed that their properties are predetermined.

Conventions also exist for the interpretation of drawings. A great deal of foreknowledge is required about the nature of solid objects, none of which appears in an architect's plan, all of which is necessary for its sensible interpretation. For example, the knowledge that solid objects occlude one another is often required, yet it is not stated in an architectural plan. In a drawing originating from some indigenous artists of Australia, exactly the opposite is assumed - namely that the innards of a creature will be depicted as clearly as the boundary line representing the skin. (Alternatively, perhaps the omission of some skin is akin to the omission of the roof of a house in a plan view).

In the last few hundred years of Western musical history, the individual musical event has found an 'elemental' character, the note. Much music has nevertheless deviated from this path, especially in the exploration of electronics for the synthesis of new timbres and forms, but also for acoustic 
music. For the sake of simplicity, such notations are not discussed here, although equivalent statements may be made concerning their importance for generative art.

The elemental nature of the musical note facilitates its specification using abstract symbols. Musical works can be represented by placing a selection from a finite alphabet of marks on a page in one of an infinite variety of possible combinations, usually with a selection from a finite alphabet of modifier symbols. What results is a description of a series of sound-events chosen from an infinite variety of possible compositions. This is conveyed by what amounts to a language for the representation of music.

To return now to the drawing or plan, there are an infinite number of possible drawings and also an infinite number of possible lines, points and other marks which may be made on a page. There is no guarantee that a given drawing will be ambiguous, nor that it will actually represent any physical object at all. The relatively unconstrained drawing is not a suitable equivalent for musical notation. What is required is a means of specifying the form of a solid object using a well-defined alphabet, an unambiguous (or at least controllably ambiguous) notation, a spatial staff.

\section{Spatial Notation}

If the musical note is the atom of (much) Western music and the staff the measure against which it is recorded, the Cartesian point and axes are their spatial counterparts. The Cartesian coordinate system (or any equivalent that specifies a unique location in space with respect to some origin) therefore provides one possibility for notation in visual art, and a means of creating and manipulating symbols which represent changes in physical structure or form. Once a conventional notation can identify a location in space, representations for solid objects may also be constructed and manipulated. This may occur by connecting points with edges or faces, by defining volumes of solid matter or empty space with equations, or in a myriad of other ways.

Cartesian coordinates, like their musical counterparts, are powerful but certainly not always desirable or helpful ways of representing a form. Nevertheless the system has its place. Certain kinds of structures lend 
themselves to representation using Cartesian coordinates. For instance a traditional mobile's configuration can be specified in terms of the end-points of each of its rods and wires. If the items suspended beneath the rods are circular discs, these may be specified in terms of their position, radius and the orientation of a surface normal-vector. A solid form may be specified in terms of the volume it fills or its surface extent using a mathematical expression or a sequence of locations and a method for connecting them. Each of these schemes may be specified in a computer in terms of points in space defining volume-element locations, polygons, spline-patch control-points, implicit surfaces or in a variety of other ways.

Points and notes then provide one means by which representations for physical and musical form may be constructed. These elements may be utilized in algorithmic composition, the topic of the following section.

\section{Algorithmic Notation}

The digital arts share a common basis in the underlying manipulation of binary switches. Like all physical processes, this manipulation occurs within the constraints imposed by physical law. The switches are not (usually) conceived of as such but as sequences of ones and zeros, as machine code, or even as high-level programming code. It is not (usually) the ones, zeros or code which is of interest in the electronic arts, but the things they represent. Since representation is determined by convention, the meaning of the symbols manipulated by the physical process is constructed by an observer. The changing meaning of the system's state at each stage of the physical process is itself a process - an abstract one. This is true even though, as always, the process of manipulating the representors must be physical.

Computer programs deal with the manipulation of symbols represented as switching patterns, but the viewer of a digitally-conceived artwork need never know this because the machine's symbols may be presented as aural or visual stimuli. Similarly, the photographer and viewer of a photograph remain unaware of the many millions of chemical interactions which go on when light hits the surface of film as the shutter slides across it. However the computer programmer does not have this freedom from dealing with the underlying processes. The programmer constructs processes by manipulating 
their symbolic representations. This unavoidable need to dabble with basic interactions is the bread and butter of programming work. Although in some cases even the interactions at the level of hardware are not abstractions which the programmer ignores, usually high-level language symbols provide sufficient detail to realize processes which run efficiently on a given piece of hardware.

From here springs the idea of "generative processes in the electronic arts". The avenues for exploring process-based/generative art are: (i) through the physical world and (ii) through the abstract or conceptual one. The physical world is exceedingly (if not infinitely) complex. Although a process might be imagined by an artist, it may be that this process could never be satisfactorily encapsulated in an artefact due to the constraints imposed by physics and chemistry.

Abstract, conceptual processes on the other hand, are beautiful to those mathematicians, logicians, poets, philosophers, computer scientists and others well-versed in their language. These specialists are (sometimes) able to visualize a complex dynamic entity from its description... but this approach to art-making has a limited audience and consequently a limited appeal. The computer, through its ability to express dynamics and give concrete visual and aural form to abstraction, is ideally suited to the production of art which may be experienced. This is abstraction made tangible, as opposed to a conceptual art devised purely for the mind.

\section{Conclusion}

In summary then, processes may be employed by an artist to construct or specify stable artefacts such as a painting, or they may produce a set of instructions for interpretation in order to generate a process which is then experienced as a work of art. Alternatively, a process may be initiated and left to follow its own course, during which time people may interact with it or not, as they choose.

Complex physical processes are notoriously difficult to control. The computer, with its limited set of instructions and operations, but with its huge capacity for the manipulation of representors, provides a practical alternative 
for the artist interested in exploring generative processes, their outcomes, their execution and the interaction between them and human observers.

The Centre for Electronic Media Art at Monash University in Melbourne Australia, and the Iteration conference series were created to focus on issues such as those raised above. It is the hope of the author that readers will have had their interest sufficiently piqued to make further enquires through the web site and email addresses listed in the text.

\section{Acknowledgments}

Thank you to Jon McCormack, partner in crime at Monash University, in CEMA and Iteration for his comments on this paper. I am sure there are still plenty of things in here with which he healthily disagrees.

Finally, the author wishes to beg the forgiveness of the reader who has made it this far and to thank him or her for persevering with this wordy and rambling stream of thought.

\section{Bibliography}

Brown, P. 1999. Stepping stones in the mist, in First Iteration: Proceedings of the first international conference on generative systems in the electronic arts, CEMA, Dorin \& McCormack (eds.) Melbourne, December

Dorin, A. and McCormack, J. (eds.) 1999. First Iteration: Proceedings of the first international conference on generative systems in the electronic arts, CEMA, Melbourne, December

Dorin, A. 1999. Classification of physical processes for virtual-kinetic art, in First Iteration: Proceedings of the first international conference on generative systems in the electronic arts, Dorin \& McCormack (eds.) CEMA

Hindley G. (ed.) 1987. The Larouse Encyclopedia of Music, Hamlyn

Lescinsky, G. 1992. Shroud, in The Third Symposium on Electronic Arts, exhibited at Australian Centre for Photography, Sydney, Australia, 9-13 November 
McCabe, J. 1999. Blue Man, in electronic theatre, at First Iteration: first international conference on generative systems in the electronic arts, Dorin \& McCormack (eds.) CEMA

McCormack, J. 1994a, Turbulence, in Visual Proceedings of SIGGRAPH 94, ACM, New York (New York)

McCormack, J. 1994b. Wild, in Next Wave art \& technology catalogue, Next Wave Festival Inc., Melbourne, Australia

Ramsden, S. 1994, Vanishing point at the event horizon, in Contours of the Mind: A celebration of fractals, feedback and chaos, an exhibition of sonic and visual Art, Drill Hall Gallery, Australian National University, 23 June - 24 July

Spector, N. (ed.) 1998, Guggenheim Museum: A to Z, Guggenheim Museum Publications

Tonkin, J. 1993. air, water, pt. 2, Issue 92, SIGGRAPH 93, Small animation theatre art reel

Tonkin, J. 1999. Personal Eugenics, in Process Philosophies, at First Iteration, the first international conference on generative systems in the electronic arts, Monash University, Melbourne 